\title{
Tay-Sachs Disease: Ultrastructural Studies on Cultured Fibroblasts
}

\author{
PHILIP R. WYATT, ${ }^{(20)}$ DAVID M. COX, AND JAN HOOGSTRATEN \\ Albert B. Chandler Medical Center, University of Kentucky, Lexington, Kentucky, USA (P.R.W).; Departments \\ of Anatomy and Pediatrics (D.M.C.), and Department of Pathology (J.H.), Children's Centre, \\ Health Sciences Center, Winnipeg, Manitoba, Canada
}

\begin{abstract}
Summary
The knowledge that the biochemical lesion associated with Tay-Sachs disease is demonstrable in many tissues, and in particular in cultured fibroblasts, suggested that ultrastructural lesions might also accompany hexosaminidase $A$ deficiency in cultured fibroblasts. Electron microscopic studies on six human skin fibroblast lines and four amniotic fluid fibroblast lines, biochemically confirmed to be deficient in hexosaminidase $A$, showed characteristic cytoplasmic inclusions not observed in any normal lines studied. Up to 60 of these abnormal cytoplasmic inclusions were observed in full cell cross sections in all affected lines examined.
\end{abstract}

\section{Speculation}

Electron microscopy of cultured fibroblasts deficient in hexosaminidase A may have value in the understanding of the cellular processes which led to Tay-Sachs disease. Ultrastructural examination may also prove to be of value in the prenatal diagnosis of the disease and possible enzyme replacement therapy.

Tay-Sachs disease, also termed $\mathrm{Gm}_{2}$ gangliosidosis type $\mathrm{I}$, is an autosomal recessive condition which is found predominantly among decendants of Ashkenazie Jews (11). The frequency of carriers in these populations is approximately 1 in 30 and the frequency of affected individuals approximately 1 in 4000 live births in this ethnic group (16). Individuals affected with TaySachs disease usually die by 5 years of age.

The biochemical abnormality in this disease has been determined to be a marked deficiency in the enzyme hexosaminidase A which, because of the altered metabolic activity, leads to the accumulation of ganglioside $\mathrm{Gm}_{2}$ in numerous tissues of the affected individual (13). The accumulation of ganglioside $\mathrm{Gm}_{2}$ has also been detected in cultured cells (2). Biochemical assay of the activity of hexosaminidase $A$ has been determined in liver, brain, skin, kidney, leukocytes, serum, cultured fibroblasts, and amniotic fluid cells $(6,13)$. In addition, electron microscopic examination of neuronal cells from children affected with Tay-Sachs disease has shown the presence of numerous membraneous cytoplasmic bodies which are composed of concentrically arranged membranes, closely packed together (16). Some investigators consider these inclusions to be characteristic for the disease (12). The bodies measure between 0.5 and 2.0 $\mu \mathrm{m}$ in diameter and have been demonstrated to be the site of acid phosphatase activity, indicating their probable lysosomal origin (17). Chemical analysis demonstrates that they contain large quantities of ganglioside $\mathrm{Gm}_{2}(15)$.

The knowledge that the biochemical lesion associated with Tay-Sachs disease is demonstrable in many tissues and, in particular, in cultured fibroblasts, suggested that ultrastructural lesions might also accompany hexosaminidase A deficiency in cultured fibroblasts. To investigate this possibility, an electron microscopic examination was made of cultured cells known to be deficient in hexosaminidase $A$.

We have demonstrated that cultured fibroblasts derived from individuals affected with Tay-Sachs disease have distinct morphologic aberrations which are not observed in normal fibroblasts. Thus, it should now be possible to investigate this disease by means of ultrastructural examination of cultured fibroblasts.

\section{MATERIALS AND METHODS}

A total of 15 normal cultured human skin fibroblast lines and 13 normal cultured human amniotic fluid fibroblast lines were utilized to establish the ultrastructural appearance of normal fibroblasts. These fibroblast lines were all of low passage number, the highest studied being the $18 \mathrm{th}$. Six human skin fibroblast lines derived from individuals biochemically confirmed to be affected with Tay-Sachs disease were examined at low passage number, the highest being the 15 th. Two human skin fibroblast lines derived from individuals heterozygotic for TaySachs disease were also studied at low passages. The highest passage number studied was the 14th. Four amniotic fluid fibroblast lines, biochemically confirmed to be derived from amniotic fluids affected with Tay-Sachs disease, were examined, three at below the 10th passage; the fourth passage number was unknown. Cell lines were obtained from either the Mutant Human Cell Repository, Montreal, Quebec; The Human Genetic Mutant Cell Repository, Camden, NJ; or the Department of Pathology, Deer Lodge Hospital, Winnipeg, Manitoba.

Between $2.0 \times 10^{5}$ and $4.0 \times 10^{5}$ cells from each fibroblast line studied were seeded into two separate $60 \mathrm{~mm}$ dishes (Falcon Plastics, Oxnard, CA) containing $4.0 \mathrm{ml} \mathrm{McCoy's} \mathrm{5a} \mathrm{(modified)}$ tissue culture medium (Schwarz BioResearch, Orangeburg, NY) supplemented with $10 \%$ fetal calf serum, (Microbiological Associates, Bethesda, MD), $5 \%$ human cord serum with added antibiotics. The dishes were then incubated at $37.5^{\circ}$ in a Napco water-jacketed incubator with a $100 \%$ humid atmosphere of $5 \% \mathrm{CO}_{2}$ in air. One of these dishes would, after the designated period of time, be processed for electron microscopy; the second would be allowed to grow to confluence and then be passaged again into two more dishes. This procedure was continued until four consecutive passages were available for ultrastructural examination for each cell line studied. For the purpose of comparison and control, the normal fibroblast lines and diseased fibroblast lines were cultured at the same time.

The dishes were examined initially for growth by light microscopy on the fourth day of culture. On day 5, the medium was changed and $4.0 \mathrm{ml}$ fresh medium were added. Twenty-four hours later, each dish was re-examined by light microscopy to ensure the monolayer was not confluent, and then processed for electron microscopy in situ in the petri dish. The cells were fixed with $5 \%$ gluteraldehyde in $0.1 \mathrm{M}$ Sorensen's buffer, washed at 
pH 7.3 in a solution of $5 \%$ sucrose in 0.1 M Sorensen's buffer, and postfixed in $1 \%$ osmium tetroxide in $0.1 \mathrm{M}$ Sorensen's buffer. Each petri dish was then passed through 2-min washes of $35 \%, 50 \%, 75 \%, 90 \%, 100 \%$ ethanol and $100 \%$ methanol. The petri dishes were filled with araldite to a depth of approximately $0.5 \mathrm{~cm}$ and placed in an oven at $60^{\circ}$ for $24 \mathrm{hr}$ to polymerize the araldite. The araldite was separated from the plastic petri dish, the cells and a surface film of the plastic dish remaining in the araldite sheet. Small segments of the araldite with the cell side facing outwards were mounted in fresh araldite on wooden supports. These wooden blocks were placed in an oven at $60^{\circ}$ for $24 \mathrm{hr}$ to polymerize the araldite.

Sections were cut in the horizontal face of the embedded monolayer of a Reichert Om U2 ultramicrotome. The sections were stained with lead citrate and uranyl acetate and viewed on a Zeiss 9AS2 electron microscope. A minimum of 150 cells or parts of cells were examined for each passage studied. In the majority of cases, many more than 150 cells were examined.

\section{RESULTS}

All the cell lines studied and reported here were examined by electron microscopy for at least four consecutive passages each.

\section{NORMAL CULTURED SKIN FIBROBLAST LINES}

The normal human cultured skin fibroblasts were generally seen to have a spindle shape, with lengths commonly between 40 and $60 \mu \mathrm{m}$ and widths varying between 6 and $13 \mu \mathrm{m}$. The overall appearance of the cells did vary, however, from the more predominant spindle shapes to virtually circular shapes. The nucleus generally occupied between $25 \%$ and $30 \%$ of the cell and followed the shape of the cell itself. The chromatin in the nusleus was usually very dispersed and was condensed only as a thin rim intimately associated with the interior of the nuclear envelope. Nucleoli were evident. The cytoplasm contained the organelles normally seen in an active cell, including ribosomes, endoplasmic reticulum, Golgi complexes, lysosomes, mitochondria, lipid storage bodies, vacuoles, microtubules, and microfilaments. The majority of the organelles were usually found in the perinuclear region of the cell. Ribosomes, microtubules, and microfilaments, however, were generally evenly distributed throughout the cell. Typically, only few lysosomes were present in a single cell section and rarely would more than

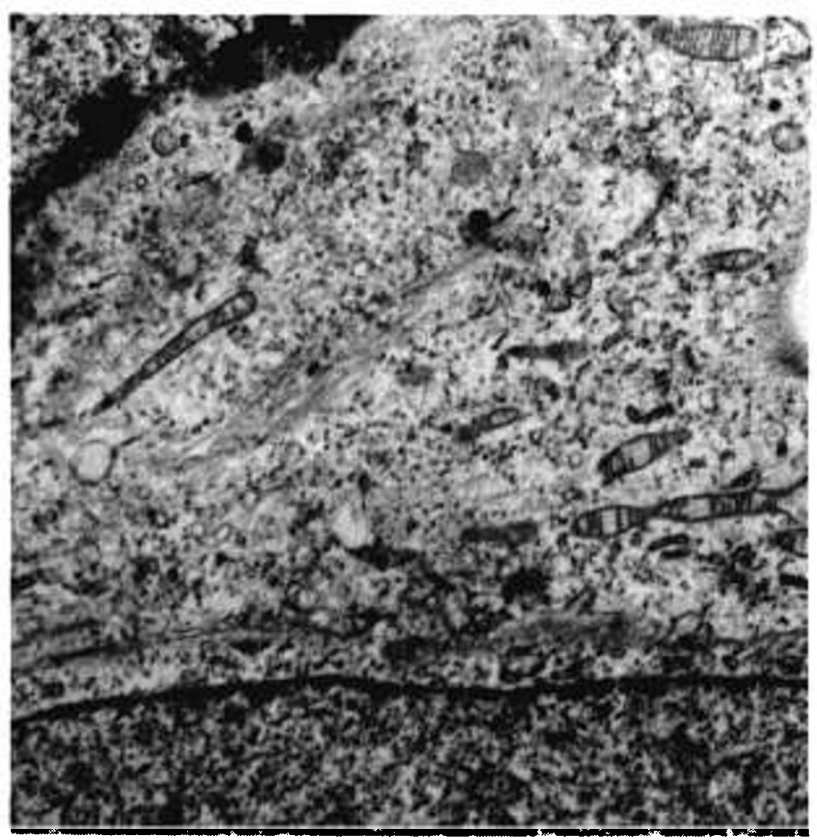

Fig. 1. Two adjacent normal cultured skin fibroblasts. Scale bar $=1$ $\mu \mathrm{m} . \times 4500$. five be seen. They showed great variation in their appearance, varying from almost translucent to opaque and were identified as lysosomes simply by the presence of a single limiting membrane (5). Normally the lysosomes would measure between 1 and $3 \mu \mathrm{m}$ and could vary widely in their internal structure within each cell and between cell lines; no consistency in the structural appearance of these bodies from passage to passage was observed. Figure 1 shows the appearance of normal cultured cells. Only very rarely were unusual and unique structures observed in the cytoplasm and these never persisted through serial passage.

\section{NORMAL CULTURED AMNIOTIC FLUID FIBROBLASTS}

The ultrastructural appearance of the amniotic fluid fibroblast was very similar to the skin fibroblast. However, some differences were noted: there was slightly more free glycogen evenly distributed throughout the cell; less evidence of pinocytosis; and the presence of up to 10 lysosomal bodies was occasionally noted in normal cultured amniotic fluid fibroblasts.

\section{SKIN FIBROBLASTS HOMOZYGOTIC FOR TAY-SACHS DISEASE}

At every passage studied for each of the six skin fibroblast lines confirmed to be deficient in the enzyme hexosaminidase A, abnormal cytoplasmic bodies were observed. These bodies were not observed in any of the normal fibroblast lines but were common to all of the Tay-Sachs cases studied. They were diverse in morphology, ranging in size from $0.5-2.0 \mu \mathrm{m}$ and varying in appearance from parallel groups of membranes to concentrically wound membranes which surrounded a central core. Generally, 6-10 of these cytoplasmic bodies were seen in a full cell cross section, although in some cell sections there were in excess of 60 whereas in others none would be observed. The quantitation of these bodies in each cell was not performed. Examples are shown in Figures 2, 3, and 4.

\section{SKIN FIBROBLASTS FROM CARRIERS OF TAY-SACHS DISEASE}

In the two cell lines derived from individuals heterozygotic for Tay-Sachs disease, cytoplasmic bodies similar to those observed in fibroblasts derived from individuals with Tay-Sachs disease were not seen nor was any abnormality observed which could distinguish these cells from normal control fibroblasts.

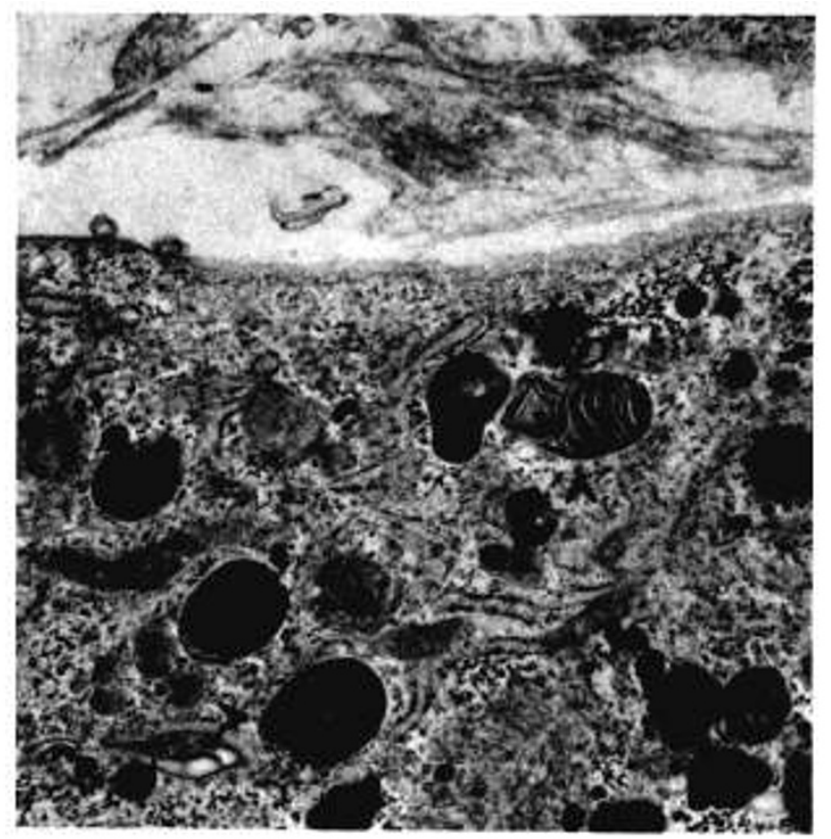

Fig. 2. Area of cytoplasm from cultured skin fibroblast affected with Tay-Sachs disease. Arrows indicate several of the cytoplasmic bodies found only in affected cells. Scale bar $=0.25 \mu \mathrm{m} . \times 11,100$. 


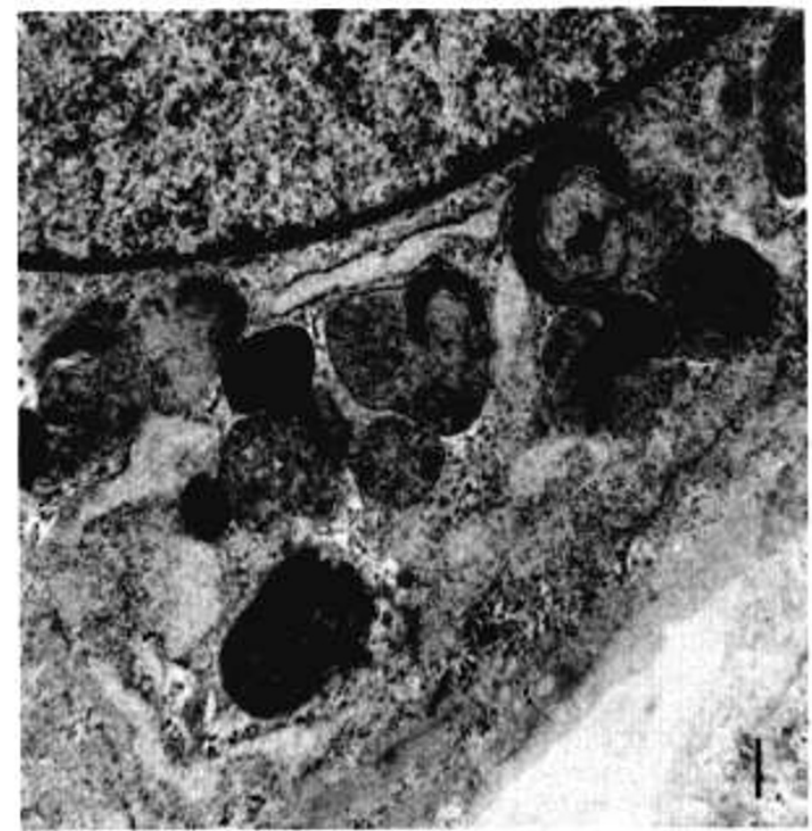

Fig. 3. Area of skin fibroblast affected with Tay-Sachs disease. Scale bar $=0.2 \mu \mathrm{m} . \times 24,800$.

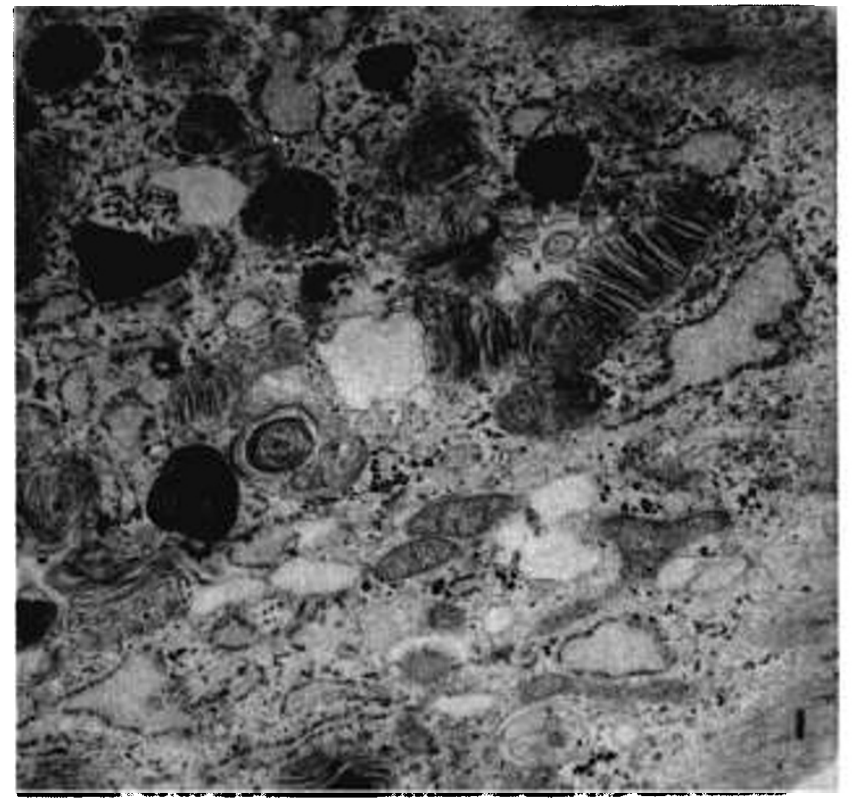

Fig. 4. Affected skin fibroblast. Note variation in appearance of membranous cytoplasmic bodies. Scale bar $=0.25 \mu \mathrm{m} . \times 10,700$.

\section{AMNIOTIC FLUID FIBROBLASTS HOMOZYGOTIC FOR TAY-SACHS DISEASE}

The four amniotic fluid fibroblast cell lines deficient for hexosaminidase $\mathrm{A}$ revealed bodies similar to those observed in postnatal skin fibroblasts derived from individuals affected with Tay-Sachs disease. They appeared consistently in each passage studied. Figure 5 illustrates several of these bodies. They varied in size from 0.4-1.8 $\mu \mathrm{m}$, and, as was seen in the postnatal skin fibroblasts, showed variation in their internal structure. No normal amniotic fluid fibroblast showed any evidence of such bodies.

\section{AMNIOTIC FLUID FIBROBLASTS FROM CARRIERS OF TAY-SACHS DISEASE}

Heterozygotic amniotic fluid fibroblast lines were not available for study.

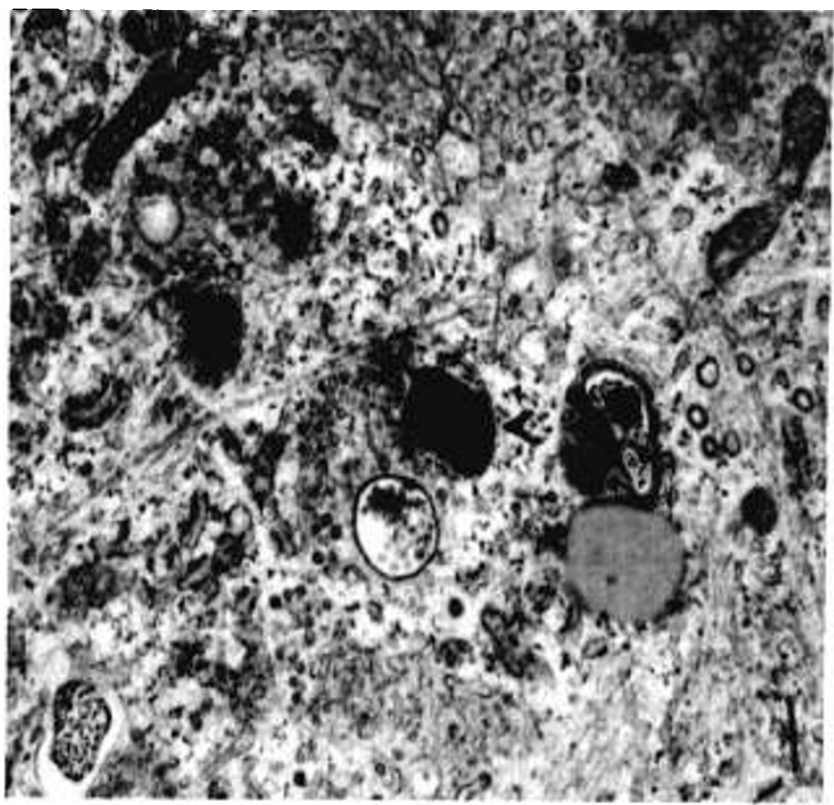

Fig. 5. Area of cytoplasm from cultured amniotic fluid fibroblast affected with Tay-Sachs disease. Arrow indicates one of membranous cytoplasmic bodies evident. Scale bar $=0.2 \mu \mathrm{m} . \times 23,800$.

\section{DISCUSSION}

Studies on the normal uttrastructure of cultured human fibroblasts are surprisingly sparse in light of the considerable use of these cells for both cytogenetic and biochemical diagnoses. This paucity of information in regard to the morphology of the cultured fibroblast may be related to the great variation which is apparently observed in their normal appearance. Some authors have reported normal cells to be filled with cytoplasmic inclusions when studied at confluency or when studied under various extremes of culture $(4,8,10)$. In addition, it has been suggested that normal cells can even mimic pathologic conditions (9). It must be appreciated that each of these studies differs from the other as to the culture conditions used and the methods of fixation of the cells, and it is difficult therefore, to compare their results. However, certain general statements can be made. First, cells studied in the stationary growth phase, having been maintained at confluence, show a dramatic increase in the number of unusual cytoplasmic bodies present in the cell. It has been shown that cells studied before they have reached stationary phase have relatively few of these cytoplasmic bodies. Second, indications are that in cultures of high passage number (those approaching senescence of the cell line), the cells show large accumulations of unusual cytoplasmic bodies. Third, the ultrastructural appearance of human cultured fibroblasts has been shown to change under different culture conditions (7). This is to be expected as variations are observed in any laboratory test when conditions are altered.

In the light of these considerations, throughout this study, in order to minimize the number of such induced cytoplasmic bodies, the fibroblasts were examined before attaining confluence, only cultures of low passage number were used, and standardized culture procedures were employed. That the normal cell lines were shown to be relatively uniform in their appearance from passage to passage indicates that control of culturing variables can make it possible to establish a baseline appearance for the ultrastructure of the cultured fibroblast.

The demonstration that cultured fibroblasts derived from individuals affected with Tay-Sachs disease have distinct morphologic aberrations which are not observed in normal fibroblasts makes it possible to utilize the ultrastructural examination of cultured fibroblasts in the investigation of Tay-Sachs disease. This is important for two reasons. First, it provides a second 
method for confirmation of the disease, thus complementing current biochemical methods of diagnosis. The relevance of this in the developing field of prenatal diagnosis has been recently described (18). Second, it may prove to be of value in the possible development of enzyme replacement therapy. For example, it has been recently demonstrated that hexosaminidase $A$, incorporated in liposomes, can be successfully taken up by the polymorphonuclear leukocytes of a patient with Tay-Sachs disease, indicating the possibility of replacement therapy in blood cells (3). However, since it has been demonstrated that irreversible brain damage has already occurred by 16 weeks of gestation (14), treatment must be administered early in gestation. Since we have demonstrated that Tay-Sachs disease can be detected morphologically in amniotic fluid fibroblasts, it may now be possible to study the incorporation of liposomes into fetal fibroblasts from early stages of pregnancy. The efficacy of such an approach might well be assessed by use of the experimental animal systems which are now available (1), in which the accessibility of liposomes to the amniotic fluid fibroblasts, and ultimately to the fetal neuronal cells, could be tested.

\section{CONCLUSION}

This report demonstrates that it is possible to distinguish cultured fibroblasts affected with Tay-Sachs disease from normal cultured fibroblasts based on ultrastructural appearance. It is possible to use this morphologic difference to distinguish affected amniotic fluid fibroblasts from normal amniotic fluid fibroblasts.

\section{REFERENCES AND NOTES}

1. Baker, H. J., Mole, J. A. Lindsey, J. R. et al.: Animal models of human ganglioside storage disease. Fed. Proc., 35: 1193 (1976).

2. Batzdorf, U., Squlieve, L. L., Gold, V. A., et al.: Tay-Sachs disease demonstration of the stored ganglioside in cultured cells from brain biopsy. Arch. Neurol.. 20: 650 (1969).

3. Cohen, C. M., Weissmann, G., Hoffstein, S., et al.: Introduction of purified hexosaminidase $\mathrm{A}$ into Tay-Sachs leukocytes by means of immunoglobulincoated liposomes. Biochemistry 15: 452 (1976).
4. Comings, D. E., and Okada, T. A.: Electron microscopy of human fibroblasts in tissue culture during logarithmic and confluent stages of growth. Exp. Cell Res., 61: 295 (1970).

5. Dingle, J. T.: Lysosomes: A Laboratory Handbook (North-Holland, Amsterdam, 1972).

6. Friedland, J., Perle, G., Saifer, A., et al.: Screening for Tay-Sachs disease in utero using amniotic fluid. Proc. Roy. Soc. Exp. Med., 136: 1297 (1971).

7. Lie, S. O., Schofield, B. A. Taylor, H. A., et al.: Structure and function of lysosomes of human fibroblasts in culture: Dependence on Medium $\mathrm{pH}$. Pediat. Res., 7: 13 (1973).

8. Lipetz, J., and Cristofalo, V. J.: Ultrastructural changes accompanying the aging of human diploid cells in culture. J. Ultrastruct. Res., 39: 43 (1972).

9. Lucky, A. W., Mahoney, M. J., Barnett, R. J., et al.: Electron microscopy of human skin fibroblasts in situ during growth in culture. Exp. Cell. Res., 92: 383 (1975).

10. Maciera-Coelho, A., Garcia-Giratt, E., and Adrian, M.: Changes in lysosomal associated structures in human fibroblasts kept in the resting phase. Proc. Soc. Exp. Biol. Med., 138: 712 (1971).

11. McKusick, V.: Mendelian Inheritance in Man (Johns Hopkins University Press, Baltimore, 1975).

12. Nelson, J. S.: Developmental disease of nervous system. In: J. M. Kissane: Pathology of Infancy and Childhood, pp. 917-953 (C. V. Mosby, St. Louis, 1975).

13. O'Brien, J. S.: Tay-Sachs disease and juvenile $\mathrm{GM}_{2}$-gangliosidosis. In: H. G. Hers and F. Van Hoof: Lysosomes and Storage Diseases, pp. 323-344 (Academic Press, New York, 1973).

14. Schneck, I., Adachi, M.j and Volk, B. M.: The fetal aspects of Tay-Sachs disease. Pediatrics, 49: 342 (1972).

15. Suzuki, K., Suzuki, K., and Samoshito, S.: Chemical pathology of $\mathbf{G M}_{\mathbf{2}}$ gangliosidosis (generalized gangliosidosis). J. Neuropath. Exp. Neurol., 28: 25 (1969).

16. Volk, B. M., Adachi, M., and Schneck, L.: The gangliosidoses. Human Pathol. 6: 555 (1975).

17. Wallace, R. J., Volk, B. W., and Lazarus, S. S.: Fine structural localization of acid phosphatase activity in neurons of Tay-Sachs disease. J. Neuropathol. Exp. Neurol., 53: 676 (1964).

18. Wyatt, P. R., and Cox, D. M. The utilization of electron microscopy in the prenatal diagnosis of genetic disease. Human Hered., 27: 22 (1977).

19. This research was supported by the Medical Research Council of Canada and the Children's Hospital of Winnipeg Research Foundation, Inc.

20. Requests for reprints should be addressed to: Philip R. Wyatt, Ph.D., Albert B. Chandler Medical Center, Department of Pediatrics, MN 466, University of Kentucky, 800 Rose, Lexington, KY 40506 (USA)

21. Received for publication January $18,1977$.

22. Accepted for publication July 29, 1977. 